\title{
Screening supportive care needs, compliance with exercise program, quality of life, and anxiety level during the COVID-19 pandemic in individuals treated with hematopoietic stem cell transplantation
}

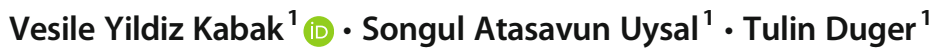 \\ Received: 14 August 2020 / Accepted: 16 December 2020 / Published online: 6 January 2021 \\ (C) The Author(s), under exclusive licence to Springer-Verlag GmbH, DE part of Springer Nature 2021
}

\begin{abstract}
Purpose The primary aim was to assess supportive care needs, compliance with home exercise program, quality of life level (QOL), and anxiety level during the COVID-19 pandemic in individuals treated with hematopoietic stem cell transplantation (HSCT). The secondary aim was to investigate demographic and medical factors associated with the recorded outcomes.

Methods The present study included individuals treated with HSCT and previously referred to physical therapy. The data were collected by interviews with the participants on the phone. Supportive care needs were assessed using the Supportive Care Needs Survey-Short Form $29^{\mathrm{TR}}$. Compliance with the exercise program was recorded as the number of patients regularly performed strengthening and stretching exercises and the ratio of the walking duration to the recommended duration. The European Cancer Research and Treatment Organization Quality of Life Questionnaire-Cancer30 was used to assess the QOL. The State-Trait Anxiety Inventory-I and the Visual Analogue Scale were used to assess anxiety level.

Results The present study included 101 individuals treated with HSCT. The psychological and physical supportive care needs were predominant in participants. Compliance with exercise program was low. General anxiety level was low, yet anxiety about COVID-19 was moderate level in participants. Supportive care needs were related to female gender, performance level, time since HSCT, and QOL level $(p<0.05)$. Anxiety level was correlated with supportive care needs, COVID-19-related anxiety, and QOL $(p<0.05)$. Compliance with exercise program was associated with age, performance level, and QOL $(p<0.05)$.

Conclusion Our results offer that supportive telehealth interventions should be considered during the COVID-19 pandemic for individuals treated with HSCT to decrease unmet supportive care needs and isolation-related physical inactivity.
\end{abstract}

Keywords Supportive care · Quality of life · Hematopoietic stem cell transplantation · COVID-19

\section{Introduction}

The current COVID-19 pandemic has been affecting a wide range of populations and has led to challenges in healthcare and supportive care services. During the pandemic, several changes have occurred in the diagnosis, treatment, and supportive care options of various diseases. Face-to-face appointments have been generally postponed except for critical conditions. Due to the increased risk of getting infection, hospital visits have been considerably limited [1,2]. Similar changes

Vesile Yildiz Kabak

vesile_yldz@hotmail.com; vesile.yildiz@hacettepe.edu.tr

$1 \quad$ Hacettepe University Faculty of Physical Therapy and Rehabilitation, 06100 Ankara, Turkey have occurred in the follow-up procedures of patients treated with hematopoietic stem cell transplantation (HSCT). Immunosuppression is highly prevalent in this patient population as a side effect of transplantation and received treatments [3]. For these reasons, patients treated with HSCT have been considered a serious risk group for COVID-19 in recent studies [4].

Because cancer survivors' follow-up appointments were generally postponed, this would lead to insufficiency in the management of the disease and treatment-related complications. As a result of these challenges, cancer survivors may have several concerns regarding their health during the COVID-19 pandemic $[1,5]$. It has been reported that emotional status and quality of life (QOL) may have been adversely affected in cancer patients during the pandemic [6-8]. Besides, social isolation during the pandemic may cause physical problems and a decrease in functionality [9]. Accordingly, 
it has been pointed out that health professionals working with cancer patients should examine patients' supportive care needs as well as their physical and psychological status during the pandemic $[1,5]$.

Since patients treated with HSCT have a higher risk of infection and disease-related complications, their problems and needs may be higher than other cancer survivors [4]. In previous studies, unique problems have been recorded in terms of supportive care needs, anxiety, and QOL in patients treated with HSCT [10-12]. To reduce these problems, exercise interventions are considered an adjuvant therapy in this population. It has become important to follow-up such patients by a physical therapist or an exercise specialist regarding exercise prescription in recent years $[13,14]$.

Isolation during the pandemic has interrupted the routine follow-up procedures and also tracking the exercise compliance in patients treated with HSCT. Accordingly, our primary aim was to determine supportive care needs, compliance with the exercise program, QOL level, and anxiety level during the COVID-19 pandemic in individuals treated with HSCT. On the other hand, demographic and/or medical characteristics including gender, age, the type of HSCT, and/or time since HSCT have been reported as predictors for side effects, emotional status, and QOL in this population $[15,16]$. Therefore, our secondary aim was to analyze differences in outcome measures in terms of demographic and medical characteristics in the participants.

\section{Methods}

The present study was performed at Hacettepe University in Turkey. Patients treated with HSCT and previously referred to physical therapy were included. Data were collected by interviews with the patients on the phone. Exclusion criteria were (1) patients not available by phone, (2) staying in the hospital when we called, (3) not willing to participate, (4) not being able to cooperate, (5) having a serious chronic disease other than cancer, and (6) being infected with COVID-19. Since graft-versus-host-disease (GVHD) causes unique problems that suppress physical, psychological, and/or cognitive functions [17-19], patients diagnosed with GVHD were also excluded to ensure a homogenous study sample. The Hacettepe University Ethical Committee approved the present study (GO 20/611). Informed consent was read to the participants on the phone, and their consent was obtained.

\section{Outcome measures}

\section{Demographic and medical information}

Age, gender, height, body weight, educational status, profession, current occupational status, and marital status of the participants were recorded. Medical data were recorded including diagnosis, time since diagnosis, comorbidity, type of HSCT, preparation regiment for HSCT (myeloablative/reduced intensity), time since HSCT, and complications associated with HSCT.

\section{Performance status}

The Eastern Cooperative Oncology Group Performance Score (ECOG) was used to evaluate the overall performance level of the participants. The ECOG globally evaluates patients' performance, and it is scored between 0 and 4 points. Higher scores indicate lower performance level [20].

\section{Supportive care needs}

The Supportive Care Needs Survey-Short Form $29^{\mathrm{TR}}$ (SCNSSF29) was used to identify the supportive care needs of the participants [21]. The SCNS-SF29 inquire about four different aspects of supportive care needs including healthcare and information (14 items), daily life ( 5 items), sexuality (3 items), and psychological needs (7 items). Each item is scored between 1 and 5 points ( $1=$ Not suitable for me, 2=Sufficient for me, 3=I need a little, 4=I need quite, and 5=I need very much). The SCNS-SF29 total score is ranging from 29 points to 145 points. Higher scores indicate a higher need for supportive care in that aspect. As an alternative, the questionnaire can also be used to determine the number of perceived unmet needs (scores of 3 or more is considered an unmet need). The survey can be applied by interviews with the individuals on the phone $[22,23]$. Besides, the participants were asked whether they needed to be informed regarding COVID-19 (Yes/No).

\section{Compliance with the exercise program}

Participants who had been previously prescribed a home exercise program $(n=60)$ were interviewed on the phone regarding their compliance with the program. The home exercise program consisted of brisk walking, strengthening, endurance, and stretching exercises, which were adjusted to the individual needs and performance level. The exercise program was adjusted to the results of the physical function tests (including manual muscle strength testing and flexibility testing for gross muscle groups, difficulties experienced in daily living activities, and/or 6-min walking test) and the symptoms experienced by the patients. According to the American College of Sports Medicine exercise guidelines for cancer patients [24], 90 to $150 \mathrm{~min} /$ week of the walking program was recommended to the patients.

The individuals were interviewed on phone regarding their compliance with the exercise prescription during the previous week. Since patients may have difficulty in remembering their 
activities, we asked only for weekly exercise compliance. Regarding compliance with the muscle strengthening and stretching exercises, participants were asked whether they continued to exercise regularly during the previous week (yes/no). Compliance with the brisk walking program was recorded as a ratio of the total minute/week they walked during the previous week to the recommended duration ( $0 \%$ compliance to $100 \%$ compliance).

\section{Quality of life level}

The European Cancer Research and Treatment Organization Quality of Life Questionnaire-Cancer30 (EORTC QLQ-C30) was used to assess health-related QOL. The questionnaire includes 30 items, which are scored between 1 (not at all) and 4 (too much) points. The EORTC QLQ-C30 consists of three sub-headings: general health, functionality, and symptoms. Higher scores represent higher general health and functional scores. On the other hand, higher scores indicate higher symptom severity [25]. The EORTC QLQ-C30 can be applied by interviews with the patients on the phone, and the Turkish version of the EORTC QLQ-C30 was found to be valid and reliable $[26,27]$.

\section{Anxiety level}

The State-Trait Anxiety Inventory-I (STAI-I) was used to determine anxiety level of the participants. The items are scored 1 (none) to 4 points (completely). The total score is between 20 points and 80 points. Higher scores indicate a higher anxiety level. The STAI-I has been adapted to the Turkish language and found valid and reliable [28]. The cutoff value has been determined as 39 points for the STAI-I [29]. Besides, the participants were asked to indicate how much worried they were regarding COVID-19 using the Visual Analogue Scale (0: not at all worried to 10: too much worried).

\section{Statistical analysis}

Statistical analysis was performed using the Statistical Program for Social Sciences (SPSS) Version 23. The level of significance was set at 0.05 for all statistical analyses, and the results were expressed as a percentage $(\%)$ or mean \pm standard deviation. The Kolmogorov-Smirnov test was used to determine the normality of distribution. Since the data did not meet the parametric assumptions, the Mann Whitney $U$ test was used to compare the numerical data. The Spearman correlation coefficient test was used to assess the associations between the recorded outcomes.

\section{Results}

Among the 108 individuals referred previously to physical therapy and responded to the phone call, a total of 101 individuals were included in the present study. Seven individuals were excluded due to the GVHD $(n=5)$, staying in the hospital for a second HSCT $(n=1)$, and being diagnosed with COVID-19 $(n=1)$. Demographic and medical characteristics of the participants were presented in Table 1. Participants were middle-aged and mainly diagnosed with multiple myeloma or lymphoma. Their mean time since HSCT was over a year. The majority of the participants treated with autologous HSCT had no comorbidity and had no HSCT-related complication.

The supportive care needs, compliance with the exercise program, QOL level, anxiety level, and differences in these measured outcomes according to gender were presented in Table 2. Compliance with the walking program was considered low in participants who have prescribed a home exercise program $(n=60)$. In addition, very few patients $(n=8,13.3 \%)$ reported that they regularly performed strengthening, endurance, or stretching exercises. Recorded outcomes were compared according to the demographic and medical characteristics in the present study. It was found that female participants had significantly lower functionality scores and higher symptom severity scores than males $(p<0.05)$. In addition, their psychological supportive care need was significantly higher than males $(p<0.05)$. There was no significant difference in the other outcome measures between female and males. A significant difference was also found within the study sample in terms of the type of transplantation. Accordingly, patients treated with allogeneic HSCT had a higher EORTC QLQ-C30 symptom severity score than that of the patients treated with autologous HSCT $(8.12 \pm 8.07$ vs. $5.12 \pm 10.79$ points; $p=$ $0.006)$. There was no other significant difference in terms of the recorded variables including diagnosis, the intensity of the preparation regimen, presence of comorbidity, HSCT-related complication, marital status, current occupational status, and educational level.

The most reported supportive care needs were presented in Fig. 1. The most common supportive care needs were uncertainty about the future, fears about the cancer spreading, worries about the results of treatment that are beyond their control, not being able to do things that they used to do, and anxiety in the participants.

Significant associated factors with the supportive care needs, compliance with the exercise program, anxiety, and QOL level were presented in Table 3. According to the correlation analysis, a negative and low correlation was found between the SCNS-SF29 and time since HSCT $(p<0.05)$. The SCNS-SF29 score was moderately and negatively correlated with the EORTC QLQ-C30 functionality and general health scores, while it was positively correlated with the EORTC QLQ-C30 symptom score $(p<0.05)$. Lastly, the SCNS- 
Table 1 Demographic and medical characteristic of participants $(n=$ 101)

\begin{tabular}{|c|c|}
\hline Outcomes & Mean \pm SD (min-max) \\
\hline Age, years & $50.83 \pm 12.04(20-70)$ \\
\hline BMI, $\mathrm{kg} / \mathrm{m}^{2}$ & $27.07 \pm 4.63(16.41-45.78)$ \\
\hline Time since diagnosis, month & $31.67 \pm 16.19(9-84)$ \\
\hline Time since HSCT, month & $17.02 \pm 10.53(1-48)$ \\
\hline \multicolumn{2}{|l|}{ Gender, $n(\%)$} \\
\hline Male & $63(62.4)$ \\
\hline Female & $38(37.6)$ \\
\hline \multicolumn{2}{|l|}{ Diagnosis, $n(\%)$} \\
\hline MM & $36(35.6)$ \\
\hline Lymphoma & $36(35.6)$ \\
\hline Leukemia & $26(25.7)$ \\
\hline MDS & $3(2.6)$ \\
\hline \multicolumn{2}{|l|}{ ECOG performance status } \\
\hline 0 : Active & $18(17.8)$ \\
\hline 1: Limited vigorous physical activity & $59(58.4)$ \\
\hline 2: Symptomatic, independent in ADL & $22(21.8)$ \\
\hline 3: Limited ADL & $2(2)$ \\
\hline \multicolumn{2}{|l|}{ Marital status, $n(\%)$} \\
\hline Married & $89(88.1)$ \\
\hline Single & $12(11.8)$ \\
\hline \multicolumn{2}{|l|}{ Education level, $n(\%)$} \\
\hline Illiterate & $5(5)$ \\
\hline Elementary school & $35(34.7)$ \\
\hline Secondary school & $9(8.9)$ \\
\hline High school & $24(23.8)$ \\
\hline Graduate & $27(26.7)$ \\
\hline Postgraduate & $1(1)$ \\
\hline \multicolumn{2}{|l|}{ Comorbidity, $n(\%)$} \\
\hline Yes & $21(20.8)$ \\
\hline No & $80(79.2)$ \\
\hline \multicolumn{2}{|l|}{ Type of comorbidity, $n(\%)$} \\
\hline Cardiopulmonary disease & $10(9.9)$ \\
\hline Chronic kidney disease & $7(6.9)$ \\
\hline Migraine & $2(2)$ \\
\hline Rheumatoid arthritis & $2(2)$ \\
\hline \multicolumn{2}{|l|}{ Type of HSCT, $n(\%)$} \\
\hline Autologous & $71(70.3)$ \\
\hline Allogeneic & $30(29.7)$ \\
\hline \multicolumn{2}{|l|}{ Preparation regiment for HSCT, $n(\%)$} \\
\hline Myeloablative & $94(93.0)$ \\
\hline Reduced intensity & $7(6.9)$ \\
\hline \multicolumn{2}{|l|}{ Complication after HSCT, $n(\%)$} \\
\hline Yes & $12(11.8)$ \\
\hline No & $89(88.1)$ \\
\hline \multicolumn{2}{|l|}{ Type of complications, $n(\%)$} \\
\hline Veno-occlusive disease & $8(7.9)$ \\
\hline Cataract & $3(2.6)$ \\
\hline Asthma & $1(1)$ \\
\hline
\end{tabular}

Table 1 (continued)

\begin{tabular}{ll}
\hline Outcomes & Mean \pm SD (min-max) \\
\hline Current occupational status & \\
Yes & $14(13.9)$ \\
No & $87(86.1)$ \\
\hline
\end{tabular}

$B M I$ body mass index, $H S C T$ hematopoietic stem cell transplantation, $M M$ multiple myeloma, $M D S$ myelodysplastic syndrome, ECOG the Eastern Cooperative Oncology Group Performance Score, $A D L$ activities of daily living

SF29 score was positively correlated with the ECOG performance score $(p<0.05)$.

The STAI-I score was positively correlated with the SCNSSF29 score and COVID-19-related anxiety $(p<0.05)$. There was also negative and moderate association between the STAI-I and the EORTC QLQ-C30 general health score $(p<0.001)$. Compliance with the home exercise program was negatively correlated with age, the ECOG performance score, and the EORTC QLQ-C30 symptom score, while it was positively correlated with the EORTC QLQ-C30 functionality and general health scores $(p<0.05)$. There was no relationship between the other recorded outcomes.

\section{Discussion}

The present study screened the supportive care needs, compliance with the home exercise program, QOL level, and anxiety level during the COVID-19 pandemic in individuals treated with HSCT. The most common supportive care needs were related to participants' psychological and physical problems. Insufficient exercise compliance was determined in patients treated with HSCT during the pandemic. Female patients were more vulnerable than males in terms of psychological needs and QOL level. In addition, patients treated with allogeneic HSCT had higher symptom severity than patients treated with autologous HSCT. Anxiety level was also low, yet COVID19-related anxiety level was moderate. Supportive care needs were associated with performance level, time since HSCT, QOL level, and the STAI-I score. The STAI-I score was also associated with anxiety regarding COVID-19 and QOL. Lastly, compliance with the home exercise program was correlated with age, performance level, and QOL.

The current and previous cancer patients have been experiencing unique challenges during the COVID-19 pandemic. It has been reported that patients treated with HSCT were more prone for getting infected with the COVID-19 due to their poor immune system [4]. Because of these unexpected outcomes, the physical and psychological impacts of the pandemic on patients with chronic illnesses have been recommended to be investigated recently [30]. Since unique 
Table 2 Supportive care needs, compliance with the exercise program, quality of life level, and anxiety level of the participants

\begin{tabular}{|c|c|c|c|c|}
\hline Outcomes & Mean $\pm \mathrm{SD}(\min -\max )$ & Female $(n=38)$ & Male $(n=63)$ & $p$ \\
\hline SCNS-SF29 total score & $50.11 \pm 14.30(29-70)$ & $52.63 \pm 14.18$ & $48.60 \pm 14.28$ & 0.122 \\
\hline ADLN & $10.33 \pm 5.27(5-19)$ & $11.07 \pm 4.96$ & $9.88 \pm 5.44$ & 0.197 \\
\hline PN & $14.72 \pm 4.63(8-22)$ & $16.13 \pm 4.38$ & $13.87 \pm 4.60$ & $0.027 *$ \\
\hline HSCIN & $21.56 \pm 6.32(12-30)$ & $21.55 \pm 6.36$ & $21.57 \pm 6.34$ & 0.722 \\
\hline $\mathrm{SN}$ & $3.49 \pm 1.13(3-9)$ & $3.86 \pm 1.49$ & $3.26 \pm 0.78$ & 0.610 \\
\hline \multicolumn{5}{|l|}{ EORTC QLQ-C30, score } \\
\hline General health & $78.54 \pm 16.00(33.33-100)$ & $76.31 \pm 15.07$ & $79.89 \pm 16.50$ & 0.164 \\
\hline Functionality & $91.88 \pm 10.82(22.22-100)$ & $88.18 \pm 13.86$ & $94.11 \pm 7.80$ & $0.003 *$ \\
\hline Symptom & $7.23 \pm 9.01(0-51.28)$ & $9.85 \pm 11.06$ & $5.65 \pm 7.16$ & $0.039 *$ \\
\hline STAI-I, score & $37.00 \pm 3.77(31-45)$ & $36.39 \pm 3.45$ & $37.38 \pm 3.93$ & 0.384 \\
\hline Anxiety regarding COVID-19 (0-10) & $4.13 \pm 1.73$ & $4.31 \pm 1.84$ & $4.03 \pm 1.66$ & 0.273 \\
\hline Compliance with home EX (yes/no), $n(\%)^{* *}$ & $8(13.3) / 52(86.6)$ & $5(14.2) / 30(85.7)$ & $3(12) / 22(88)$ & 0.557 \\
\hline Compliance with walking program $(0-100 \%)^{* *}$ & $29.14 \pm 16.30$ & $27.03 \pm 17.27$ & $30.46 \pm 15.72$ & 0.328 \\
\hline
\end{tabular}

Quality of Life Questionnaire-Cancer30, STAI-I State-Trait Anxiety Index-I, EX exercise program, Mann Whitney $U$ test, $* p<0.05 . S C N S-S F 29$ Supportive Care Needs Survey-Short Form $29^{\mathrm{TR}}$, ADLN activities of daily life need, $P N$ psychological need, $H S C I N$ healthcare service and informing need, $S N$ sexuality need, EORTC QLQ-C30 European Cancer Research and Treatment Organization. **Totally 60 patients prescribed with home exercise program

challenges may have been experienced by individuals treated with HSCT, we aimed to screen this population in the present study. On the other hand, we excluded patients diagnosed with GVHD since it causes severe physical and functional limitations as a result of joint/fascia manifestations, contractures, pain, and gastrointestinal symptoms [18, 31]. In addition to the disease-related problems, treatment of GVHD includes glucocorticoid treatment which reduces muscle strength and functional capacity [32]. Lastly, emotional and cognitive problems and/or impairments in overall QOL have been reported more severe in patients with GVHD than without GVHD [33, 34]. For these reasons, being diagnosed with
GVHD was determined as an exclusion criterion for the present study, yet further studies should determine the specific needs of these patients during the pandemic.

An assessment of the unmet supportive care needs of the participants showed that psychological and physical needs were predominant in the present study. It has been reported that physical and psychological needs may be higher than other health-related needs during the pandemic in vulnerable populations, such as cancer patients [30]. On the other hand, a similar finding has been found in a study during the prepandemic times in patients with hematologic malignancy [35]. Our results showed that patients' problems and
Fig. 1 The most reported unmet supportive care needs in patients treated with HSCT during the COVID-19 pandemic

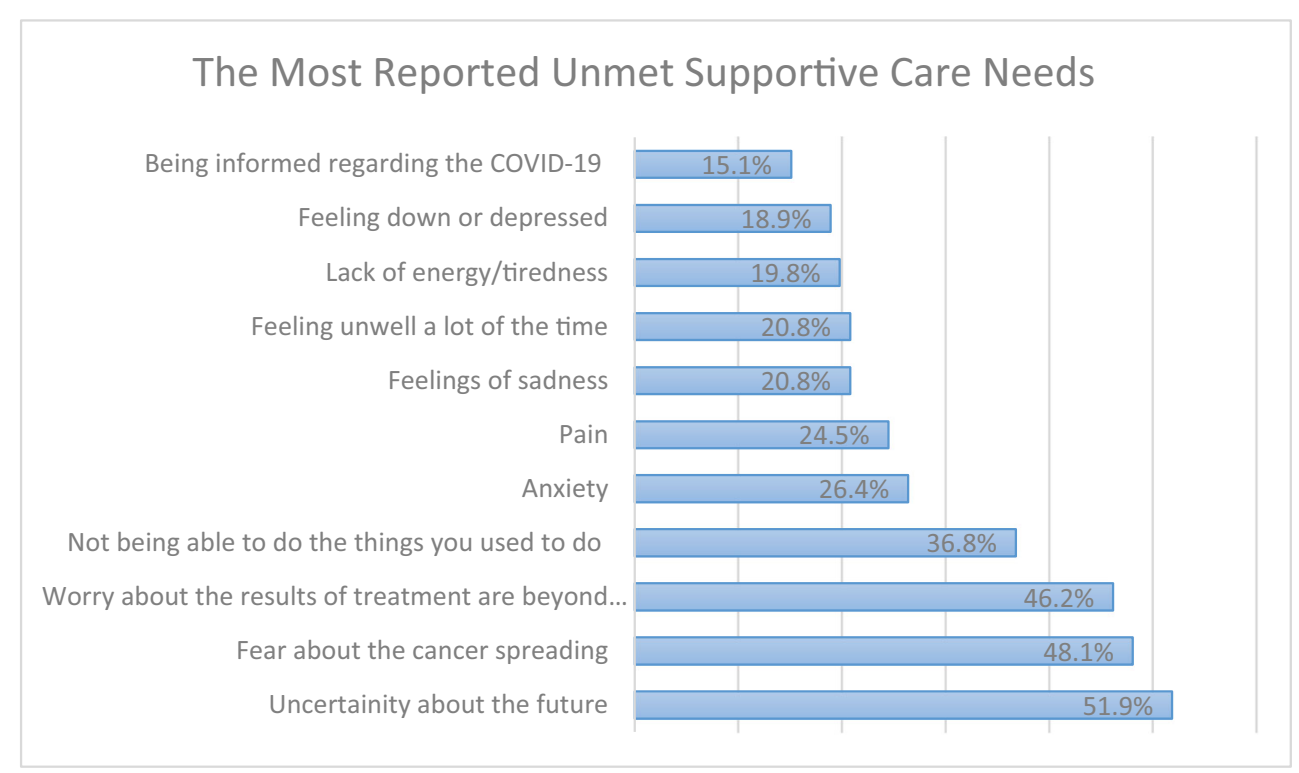


Table 3 Significant associated factors with supportive care needs, quality of life, and compliance with the exercise program during the COVID-19 pandemic

\begin{tabular}{ll}
\hline Outcomes & $R$ value \\
\hline SCNS-SF29 \& ECOG & $0.343^{* *}$ \\
SCNS-SF29 \& time since HSCT & $-0.265^{*}$ \\
SCNS-SF29 \& functionality & $-0.420^{* *}$ \\
SCNS-SF29 \& symptom & $0.483 * *$ \\
SCNS-SF29 \& general health & $-0.614^{* *}$ \\
STAI-I \& SCNS-SF29 & $0.331^{*}$ \\
STAI-I \& COVID-19-related anxiety & $0.659^{* *}$ \\
STAI-I \& general health & $-0.350^{*}$ \\
Compliance with EX \& age & $-0.238^{*}$ \\
Compliance with EX \& ECOG & $-0.395^{*}$ \\
Compliance with EX \& functionality & $0.395^{*}$ \\
Compliance with EX \& general health & $0.293^{*}$ \\
Compliance with EX \& symptom & $-0.325^{*}$ \\
\hline
\end{tabular}

SCNS-SF29 Supportive Care Needs Survey-Short Form $29^{\mathrm{TR}}$, STAI-I State-Trait Anxiety Index-I, ECOG Eastern Cooperative Oncology Group Performance Score, HSCT hematopoietic stem cell transplantation, $E X$ exercise program. Spearman correlation coefficient test, $* p<0.05, * * p<0.001$

supportive care needs continue during the pandemic. We suggest that a multidisciplinary team approach is needed to decrease supportive care needs in individuals treated with HSCT during the pandemic.

Unmet supportive care needs were further analyzed in terms of demographic and medical characteristics in the present study. Gender was found to be a significant variable for supportive care needs and QOL level. Accordingly, female participants had more supportive care needs in the psychological aspect than males, and their QOL level was also more diminished. Psychological health and QOL level were also lower in female patients than those of male treated with HSCT in a study conducted before the pandemic [15]. Regarding the supportive care needs, being female was found to be a predictor for higher unmet supportive care needs in cancer patients $[35,36]$. In these studies, gender-specific interventions have been recommended. Since our finding was similar to the studies conducted before the pandemic times, we suggest that female patients continue to need more attention during the COVID-19 pandemic, and supportive interventions or stress reduction techniques can be implemented to improve the psychological health and QOL.

Correlation analysis revealed that the supportive care needs of the participants were associated with anxiety level, performance level, and time since HSCT in the present study. As time since HSCT increased, patients' supportive care needs decreased. This trend was similar to the previous studies in which individuals had higher adverse events within the earlier period after HSCT [37]. Additionally, the results revealed that
QOL level was higher in participants who had lower supportive care needs. Accordingly, while challenges exist with meeting these needs during the pandemic, it continues to be important to meet patients' needs to increase QOL in patients treated with HSCT. Besides, since higher compliance with the home exercise program was associated with higher QOL, patients treated with HSCT should be provided with supportive care interventions including exercise programs during the pandemic. There exist sufficient data suggesting possible beneficial effects of exercise programs not only on QOL level but also on physical and psychological functions in patients treated with HSCT $[38,39]$. Telehealth technologies are now facilitated to be used by healthcare professionals to screen cancer patients' healthcare and supportive care needs $[40,41]$. The American Medical Association has encouraged the use of telehealth technologies by healthcare professionals to enhance healthcare maintenance during the COVID-19 pandemic [5]. Individuals treated with HSCT are needed to be screened regarding their health and supportive care needs during the COVID-19 pandemic. In addition, the identification of symptoms and side effects using telehealth technologies may help to prevent the occurrence of severe adverse events needing hospital visits during the pandemic [42, 43]. We suggest that patients treated with HSCT are subjected to follow-up interventions by health professionals to screen symptoms and supportive care needs during the pandemic.

Patient-reported compliance with the exercise program was considered to be low in the present study in patients who previously received home exercise prescription. This rate was lower than the other studies conducted before the pandemic in which home exercise programs were recommended to the patients treated with HSCT [44]. In our previous study conducted in a similar population in the same clinic, the number of patients reported doing regular exercise (56\%) was higher than that found in the present study (13\%) [39]. Regarding physical activity participation during the COVID19 pandemic in China, exercise participation has been considered low in the general population. In this study, it has been pointed out that health professionals should publicize the positive effects of exercise on psychological status and they should motivate the public to do regular exercise and to avoid isolation-related physical inactivity [45]. Our results showed that patients treated with HSCT had lower compliance with the exercise program than the pre-pandemic times. We suggest that patients treated with HSCT need exercise interventions during the pandemic more than ever to reduce the side effects of isolation and associated physical inactivity. Telehealth technologies can help individuals to maintain regular exercise participation and to increase their motivation. Virtual exercise programs have become more frequent during the COVID-19 pandemic and several beneficial effects of the programs have been shown. Virtual exercise sessions have been reported as an essential therapy especially for cancer 
patients during the pandemic in a study [46]. In a recent review, it has been reported that patients with cancer showed good compliance with the online exercise sessions, and patients' symptoms were reduced and their well-being also improved as a result of such interventions [47]. It seems that virtual exercise programs are a promising intervention during the pandemic especially for patients with cancer. In the present study, high age was related to lower exercise compliance. We suggest that especially patients of higher age should be screened more frequently to maintain regular exercise participation during the pandemic.

It has been reported that delayed treatments or canceled hospital visits because of the prioritization of COVID-19 cases may cause distress in cancer patients due to potentially negative outcomes of their disease [6]. While the anxiety level was not clinically serious, anxiety regarding COVID-19 was moderate in our study population. However, a comparison of the present STAI-I score with that of a previous study conducted in patients after HSCT showed that the mean score was the same (37 points) and the score was found higher than a healthy population [11]. There was no control group in the present study, which was our study limitation. On the other hand, anxiety was associated with the supportive care needs. We suggest that unmet supportive care needs may have led to emotional problems in this population. In a previous study, female participants had higher post-traumatic stress than males conducted in China during the COVID-19 outbreak [48]. Regarding the cancer population, while some studies have reported that female cancer patients had higher depression and anxiety than male during the pandemic $[7,8]$, there has been no difference between males and females in another study [49]. Since the STAI-I was not an outcome measure in these studies, it is difficult to compare our results with these studies. We suggest that the anxiety level in patients treated with HSCT should be further investigated to identify whether the main reason is related to being infected with COVID-19 or challenges regarding hospital follow-up visits.

The present study had some limitations. First of all, there is no pre-pandemic data in which we could compare our results. Secondly, since the data were collected as self-report, the results may be conflicting; e.g., patients could exaggerate, or they may experience difficulty in remembering activities. To reduce problems regarding recalling, compliance with the exercise program was asked for the previous week in the present study. According to the previous systematic review, selfreported exercise adherence assessment can be invalid; however, there exists no valid and reliable measurement method for unsupervised exercise adherence [50]. Lastly, a large portion of our study sample (nearly $40 \%$ ) had elementary education or was illiterate. Since educational level was found to be a significant predictor for exercise compliance in cancer patients [51], a low level of education in a large portion of the patients may reduce the exercise compliance in the present study.
Further studies are needed to investigate exercise compliance across patients with different sociodemographic characteristics.

In conclusion, this study provides information regarding patients treated with HSCT having unmet supportive care needs mainly psychological and physical aspect during the pandemic. Compliance with the home exercise prescription was low, and it was related with age, performance level, and QOL level. Female patients, those who had lower time since HSCT and those with a lower performance level can be considered to be a more vulnerable population in terms of unmet supportive care needs. Additionally, lower supportive care needs were related to higher QOL. Supportive telehealth interventions should be provided to individuals treated with HSCT to mitigate their physical and psychological care needs and to promote regular exercise participation during the COVID-19 pandemic. Virtual exercise interventions should be considered essential for survivors of HSCT not only to decrease symptoms and anxiety but also to reduce the side effects of isolation-related physical inactivity during the pandemic.

Authors' contributions VYK: Idea, literature research, data collection, data analysis, and manuscript writingSAU: Interpretation of findings and manuscript writingTD: Interpretation of findings and manuscript writing

\section{Data availability N/A}

\section{Compliance with ethical standards}

Conflict of interest The authors declare that they have no conflict of interest.

Ethics approval The Hacettepe University Ethical Committee approved the present study (GO 20/611).

Consent to participate Informed consent was obtained from all individual participants included in the study.

Consent for publication Written informed consent for publication of their clinical details was obtained from the participants.

Code availability N/A

\section{References}

1. Nekhlyudov L, Duijts S, Hudson SV, Jones JM, Keogh J, Love B, Lustberg M, Smith KC, Tevaarwerk A, Yu X, Feuerstein M (2020) Addressing the needs of cancer survivors during the COVID-19 pandemic. J Cancer Surviv 14:1-6. https://doi.org/10.1007/ s11764-020-00884-w

2. Chan A, Ashbury F, Fitch MI, Koczwara B, Chan RJ (2020) Cancer survivorship care during COVID-19-perspectives and recommendations from the MASCC survivorship study group. Support Care 
Cancer 28(8):3485-3488. https://doi.org/10.1007/s00520-02005544-4

3. Weinkove R, McQuilten ZK, Adler J, Agar MR, Blyth E, Cheng AC, Conyers R, Haeusler GM, Hardie C, Jackson C, Lane SW, Middlemiss T, Mollee P, Mulligan SP, Ritchie D, Ruka M, Solomon B, Szer J, Thursky KA, Wood EM, Worth LJ, Yong MK, Slavin MA, Teh BW (2020) Managing haematology and oncology patients during the COVID-19 pandemic: interim consensus guidance. Med J Aust 212(10):481-489. https://doi.org/10.5694/ mja2.50607

4. Liang W, Guan W, Chen R, Wang W, Li J, Xu K, Li C, Ai Q, Lu W, Liang H, Li S, He J (2020) Cancer patients in SARS-CoV-2 infection: a nationwide analysis in China. Lancet Oncol 21(3):335337. https://doi.org/10.1016/s1470-2045(20)30096-6

5. Marandino L, Necchi A, Aglietta M, Di Maio M (2020) COVID-19 emergency and the need to speed up the adoption of electronic patient-reported outcomes in cancer clinical practice. JCO Oncol Pract 16(6):295-298. https://doi.org/10.1200/op.20.00237

6. Young AM, Ashbury FD, Schapira L, Scotté F, Ripamonti CI, Olver IN (2020) Uncertainty upon uncertainty: supportive care for cancer and COVID-19. Support Care Cancer 28:1-4. https://doi. org/10.1007/s00520-020-05604-9

7. Romito F, Dellino M, Loseto G, Opinto G, Silvestris E, Cormio C, Guarini A, Minoia C (2020) Psychological distress in outpatients with lymphoma during the COVID-19 pandemic. Front Oncol 10: 1270. https://doi.org/10.3389/fonc. 2020.01270

8. Wang Y, Duan Z, Ma Z, Mao Y, Li X, Wilson A, Qin H, Ou J, Peng K, Zhou F, Li C, Liu Z, Chen R (2020) Epidemiology of mental health problems among patients with cancer during COVID-19 pandemic. Transl Psychiatry 10(1):263. https://doi.org/10.1038/ s41398-020-00950-y

9. Hall G, Laddu DR, Phillips SA, Lavie CJ, Arena R (2020) A tale of two pandemics: how will COVID-19 and global trends in physical inactivity and sedentary behavior affect one another? Prog Cardiovasc Dis. https://doi.org/10.1016/j.pcad.2020.04.005

10. Lobb EA, Joske D, Butow P, Kristjanson LJ, Cannell P, Cull G, Augustson B (2009) When the safety net of treatment has been removed: patients' unmet needs at the completion of treatment for haematological malignancies. Patient Educ Couns 77(1):103-108. https://doi.org/10.1016/j.pec.2009.02.005

11. Andrykowski MA, Bishop MM, Hahn EA, Cella DF, Beaumont JL, Brady MJ, Horowitz MM, Sobocinski KA, Rizzo JD, Wingard JR (2005) Long-term health-related quality of life, growth, and spiritual well-being after hematopoietic stem-cell transplantation. J Clin Oncol 23(3):599-608. https://doi.org/10.1200/jco.2005.03. 189

12. Sherman RS, Cooke E, Grant M (2005) Dialogue among survivors of hematopoietic cell transplantation support-group themes. J Psychosoc Oncol 23(1):1-24. https://doi.org/10.1300/ J077v23n01 01

13. Mohammed J, Smith SR, Burns L, Basak G, Aljurf M, Savani BN, Schoemans H, Peric Z, Chaudhri NA, Chigbo N, Alfred A, Bakhsh H, Salooja N, Chris Chim A, Hashmi SK (2019) Role of physical therapy before and after hematopoietic stem cell transplantation: white paper report. Biol Blood Marrow Transplant 25(6):e191e198. https://doi.org/10.1016/j.bbmt.2019.01.018

14. Mohammed J, Aljurf M, Althumayri A, Almansour M, Alghamdi A, Hamidieh AA, ElHaddad A, Othman TB, Bazarbachi A, Almohareb F, Alzahrani M, Alkindi SS, Alsharif F, Da'na W, Alhashmi H, Bekadja MA, Al-Shammari SH, El Quessar A, Satti TM, Aljohani N, Rasheed W, Ghavamzadeh A, Chaudhri N, Hashmi SK (2019) Physical therapy pathway and protocol for patients undergoing hematopoietic stem cell transplantation: recommendations from the eastern Mediterranean blood and marrow transplantation (EMBMT) group. Hematol Oncol Stem Cell Ther 12(3):127-132. https://doi.org/10.1016/j.hemonc.2018.12.003
15. Morishita S, Kaida K, Yamauchi S, Wakasugi T, Yoshihara S, Taniguchi K, Ishii S, Ikegame K, Kodama N, Ogawa H, Domen K (2013) Gender differences in health-related quality of life, physical function and psychological status among patients in the early phase following allogeneic haematopoietic stem cell transplantation. Psycho-oncology 22(5):1159-1166. https://doi.org/10.1002/ pon. 3128

16. Wong FL, Francisco L, Togawa K, Bosworth A, Gonzales M, Hanby C, Sabado M, Grant M, Forman SJ, Bhatia S (2010) Long-term recovery after hematopoietic cell transplantation: predictors of quality-of-life concerns. Blood 115(12):2508-2519. https://doi.org/10.1182/blood-2009-06-225631

17. Hayakawa J, Miyamura D, Kimura SI, Gomyo A, Tamaki M, Akahoshi Y, Harada N, Ugai T, Kusuda M, Kameda K, Wada H, Ishihara Y, Kawamura K, Sakamoto K, Sato M, Terasako-Saito K, Kikuchi M, Nakasone H, Kako S, Kanda Y (2019) Negative impact of chronic graft-versus-host disease and glucocorticoid on the recovery of physical function after allogeneic hematopoietic stem cell transplantation. Bone Marrow Transplant 54(7):994-1003. https:// doi.org/10.1038/s41409-018-0365-4

18. Hamada R, Kondo T, Murao M, Miyasaka J, Yoshida M, Nankaku M, Kanda J, Takaori-Kondo A, Ikeguchi R, Matsuda S (2020) Effect of the severity of acute graft-versus-host disease on physical function after allogeneic hematopoietic stem cell transplantation. Support Care Cancer 28(7):3189-3196. https://doi.org/10.1007/ s00520-019-05124-1

19. Baird K, Steinberg SM, Grkovic L, Pulanic D, Cowen EW, Mitchell SA, Williams KM, Datiles MB, Bishop R, Bassim CW, Mays JW, Edwards D, Cole K, Avila DN, Taylor T, Urban A, Joe GO, Comis LE, Berger A, Stratton P, Zhang D, Shelhamer JH, Gea-Banacloche JC, Sportes C, Fowler DH, Gress RE, Pavletic SZ (2013) National Institutes of Health chronic graft-versus-host disease staging in severely affected patients: organ and global scoring correlate with established indicators of disease severity and prognosis. Biol Blood Marrow Transplant 19(4):632-639. https:// doi.org/10.1016/j.bbmt.2013.01.013

20. Azam F, Latif MF, Farooq A, Tirmazy SH, AlShahrani S, Bashir S, Bukhari N (2019) Performance status assessment by using ECOG (eastern cooperative oncology group) score for cancer patients by oncology healthcare professionals. Case Rep Oncol 12(3):728-736. https://doi.org/10.1159/000503095

21. Boyes A, Girgis A, Lecathelinais C (2009) Brief assessment of adult cancer patients' perceived needs: development and validation of the 34-item supportive care needs survey (SCNS-SF34). J Eval Clin Pract 15(4):602-606. https://doi.org/10.1111/j.1365-2753. 2008.01057.x

22. Özbayır T, Geçkil ÖS, Aslan A (2017) An adaptation of the shortform supportive care needs survey questionnaire (SCNS-SF 34) into Turkish. Eur J Breast Health 13(4):183-188. https://doi.org/ 10.5152/tjbh.2017.3266

23. McElduff P, Boyes A, Zucca A, Girgis AJNCfHR, Psychooncology (2004) Supportive care needs survey: a guide to administration, scoring and analysis

24. Wolin KY, Schwartz AL, Matthews CE, Courneya KS, Schmitz $\mathrm{KH}$ (2012) Implementing the exercise guidelines for cancer survivors. J Support Oncol 10(5):171-177. https://doi.org/10.1016/j. suponc.2012.02.001

25. Aaronson NK, Ahmedzai S, Bergman B, Bullinger M, Cull A, Duez NJ, Filiberti A, Flechtner H, Fleishman SB, de Haes JC et al (1993) The European Organization for Research and Treatment of Cancer QLQ-C30: a quality-of-life instrument for use in international clinical trials in oncology. J Natl Cancer Inst 85(5):365-376. https://doi.org/10.1093/jnci/85.5.365

26. Guzelant A, Goksel T, Ozkok S, Tasbakan S, Aysan T, Bottomley A (2004) The European Organization for Research and Treatment of Cancer QLQ-C30: an examination into the cultural validity and 
reliability of the Turkish version of the EORTC QLQ-C30. Eur J Cancer Care 13(2):135-144. https://doi.org/10.1111/j.1365-2354. 2003.00435.x

27. Wintner LM, Sztankay M, Giesinger JM, Aaronson NK, Bottomley A, Velikova G, Verdonck-de Leeuw IM, van der Poll-Franse L, Grønvold M, Petersen MA (2016) Manual for the use of EORTC measures in daily clinical practice

28. Le Compte WA, Oner NJC-ca (1976) Development of the Turkish edition of the State-trait anxiety inventory 1:51-67

29. Spielberger C, Gorsuch R, Lushene R, Vagg P, Jacobs GJC, USA (1983) Manual for the state-trait anxiety inventory (STAI) Consulting Psychologists Press: Palo Alto

30. Kang C, Yang S, Yuan J, Xu L, Zhao X, Yang J (2020) Patients with chronic illness urgently need integrated physical and psychological care during the COVID-19 outbreak. Asian J Psychiatr 51: 102081-102081. https://doi.org/10.1016/j.ajp.2020.102081

31. Ishikawa A, Otaka Y, Kamisako M, Suzuki T, Miyata C, Tsuji T, Matsumoto H, Kato J, Mori T, Okamoto S, Liu M (2019) Factors affecting lower limb muscle strength and cardiopulmonary fitness after allogeneic hematopoietic stem cell transplantation. Support Care Cancer 27(5):1793-1800. https://doi.org/10.1007/s00520018-4433-5

32. Morishita S, Kaida K, Yamauchi S, Sota K, Ishii S, Ikegame K, Kodama N, Ogawa H, Domen K (2013) Relationship between corticosteroid dose and declines in physical function among allogeneic hematopoietic stem cell transplantation patients. Support Care Cancer 21(8):2161-2169. https://doi.org/10.1007/s00520-0131778-7

33. Fraser CJ, Bhatia S, Ness K, Carter A, Francisco L, Arora M, Parker P, Forman S, Weisdorf D, Gurney JG, Baker KS (2006) Impact of chronic graft-versus-host disease on the health status of hematopoietic cell transplantation survivors: a report from the bone marrow transplant survivor study. Blood 108(8):2867-2873. https://doi.org/ 10.1182/blood-2006-02-003954

34. Pidala J, Kurland B, Chai X, Majhail N, Weisdorf DJ, Pavletic S, Cutler C, Jacobsohn D, Palmer J, Arai S, Jagasia M, Lee SJ (2011) Patient-reported quality of life is associated with severity of chronic graft-versus-host disease as measured by NIH criteria: report on baseline data from the chronic GVHD consortium. Blood 117(17):4651-4657. https://doi.org/10.1182/blood-2010-11319509

35. Boyes AW, Clinton-McHarg T, Waller AE, Steele A, D'Este CA, Sanson-Fisher RW (2015) Prevalence and correlates of the unmet supportive care needs of individuals diagnosed with a haematological malignancy. Acta Oncol 54(4):507-514. https://doi.org/10. 3109/0284186x.2014.958527

36. McDowell ME, Occhipinti S, Ferguson M, Dunn J, Chambers SK (2010) Predictors of change in unmet supportive care needs in cancer. Psycho-oncology 19(5):508-516. https://doi.org/10.1002/pon. 1604

37. Braamse AM, van Meijel B, Visser O, Huijgens PC, Beekman AT, Dekker J (2014) Distress, problems and supportive care needs of patients treated with auto- or allo-SCT. Bone Marrow Transplant 49(2):292-298. https://doi.org/10.1038/bmt.2013.155

38. Steinberg A, Asher A, Bailey C, Fu JB (2015) The role of physical rehabilitation in stem cell transplantation patients. Support Care Cancer 23(8):2447-2460. https://doi.org/10.1007/s00520-0152744-3

39. Yildiz Kabak V, Goker H, Duger T (2020) Effects of partly supervised and home-based exercise program in patients undergoing hematopoietic stem cell transplantation: a case-control study. Support Care Cancer 28:5851-5860. https://doi.org/10.1007/ s00520-020-05432-x

40. Elkaddoum R, Haddad FG, Eid R, Kourie HR (2020) Telemedicine for cancer patients during COVID-19 pandemic: between threats and opportunities. Future Oncol 16(18):1225-1227. https://doi.org/ 10.2217/fon-2020-0324

41. Royce TJ, Sanoff HK, Rewari A (2020) Telemedicine for cancer care in the time of COVID-19. JAMA Oncol 6:1698. https://doi. org/10.1001/jamaoncol.2020.2684

42. Basch E, Deal AM, Kris MG, Scher HI, Hudis CA, Sabbatini P, Rogak L, Bennett AV, Dueck AC, Atkinson TM, Chou JF, Dulko D, Sit L, Barz A, Novotny P, Fruscione M, Sloan JA, Schrag D (2016) Symptom monitoring with patient-reported outcomes during routine cancer treatment: a randomized controlled trial. J Clin Oncol 34(6):557-565. https://doi.org/10.1200/jco.2015.63.0830

43. LeBlanc TW, Abernethy AP (2017) Patient-reported outcomes in cancer care - hearing the patient voice at greater volume. Nat Rev Clin Oncol 14(12):763-772. https://doi.org/10.1038/nrclinonc. 2017.153

44. Hacker ED, Mjukian M (2014) Review of attrition and adherence in exercise studies following hematopoietic stem cell transplantation. Eur J Oncol Nurs 18(2):175-182. https://doi.org/10.1016/j.ejon. 2013.10.013

45. Chen P, Mao L, Nassis GP, Harmer P, Ainsworth BE, Li F (2020) Coronavirus disease (COVID-19): the need to maintain regular physical activity while taking precautions. J Sport Health Sci 9(2): 103-104. https://doi.org/10.1016/j.jshs.2020.02.001

46. Bland KA, Bigaran A, Campbell KL, Trevaskis M, Zopf EM (2020) Exercising in isolation? The role of telehealth in exercise oncology during the COVID-19 pandemic and beyond. Phys Ther 100:1713-1716. https://doi.org/10.1093/ptj/pzaa141

47. Morrison KS, Paterson C, Toohey K (2020) The feasibility of exercise interventions delivered via telehealth for people affected by cancer: a rapid review of the literature. Semin Oncol Nurs:151092. https://doi.org/10.1016/j.soncn.2020.151092

48. Liu N, Zhang F, Wei C, Jia Y, Shang Z, Sun L, Wu L, Sun Z, Zhou Y, Wang Y, Liu W (2020) Prevalence and predictors of PTSS during COVID-19 outbreak in China hardest-hit areas: gender differences matter. Psychiatry Res 287:112921. https://doi.org/10. 1016/j.psychres.2020.112921

49. Letaief-Ksontini F, Zenzri Y, Yahyaoui Y, Gabsi A, Mokrani A, Meddeb KJAoO (2020) 1573P Anxiety and depression in cancer patients during the COVID-19 pandemic: a single-centre study. 31 : S957

50. Bollen JC, Dean SG, Siegert RJ, Howe TE, Goodwin VA (2014) A systematic review of measures of self-reported adherence to unsupervised home-based rehabilitation exercise programmes, and their psychometric properties. BMJ Open 4(6):e005044. https://doi.org/ 10.1136/bmjopen-2014-005044

51. Witlox L, Velthuis MJ, Boer JH, Steins Bisschop CN, Wall EV, Meulen W, Schröder CD, Peeters PHM, May AM (2019) Attendance and compliance with an exercise program during localized breast cancer treatment in a randomized controlled trial: the PACT study. PLoS One 14(5):e0215517. https://doi.org/10.1371/ journal.pone. 0215517

Publisher's note Springer Nature remains neutral with regard to jurisdictional claims in published maps and institutional affiliations. 